\title{
PENGARUH ETOS KERJA, MOTIVASI, DAN IKLIM ORGANISASI TERHADAP KINERJA DEPARTEMEN ASSET \& OFFICE MANAGEMENT PT SEMEN BATURAJA (PERSERO) TBK
}

\author{
${ }^{1}$ Irsan Yasdianto, ${ }^{2}$ Luis Marnisah, ${ }^{3}$ Fakhry Zamzam \\ ${ }^{1}$ Manager Asset Management PT Semen Baturaja (Persero) Tbk. \\ Email: irsan.yasdianto77@gmail.com \\ ${ }^{2}$ Program Magister Universitas IGM Palembang. Email: luismarnisah@uigm.ac.id \\ ${ }^{2}$ Program Magister Universitas IGM Palembang. Email: fakhry@uigm.ac.id
}

\begin{abstract}
This research aims to know the analysis result on Work Ethics, Motivation and Organization Climate on The Performance of Asset \& Office Management Department at PT Semen Baturaja (Persero) Tbk, both partially and simultaneously. This research is a quantitative research using associative, survey and descriptive method. In analyzing data, doubled linear analysis is used. The population is all 31 personnils of Asset \& Office Management Department. The test value of work ethics, motivation and organization climate do not impact on the performance, with thitung $-0.053<\operatorname{ttabel}(0,05, n-2) 2,04523$, thitung motivation $1<\operatorname{ttabel}(0,05, n-2) 2,04523$, and thitung organizaiton climate 1,839 and $<\operatorname{ttabel}(0,05, n-2) 2,04523$. The test value $F$ work ethics, motivation and organization climate impacts positive on performance with Fhitung 10,251 > F tabel(2, n-2) 2,93. Correlation Coefficient $(R)$ 0,730 shows strong positive relation and determination coefficient ( $R 2$ ) 0,532 shows 53,2\% from performance variable of Asset \& Office Department can be described by work ethics, motivation and organization climate and 46,8\% is impacted by other variables. Thus, if work ethics, motivation and organization climate increased partially, would not increase the performance of Asset \& Office Management Department, but, if it is increased simultaneously, the performance of Asset \& Office Management Department would increase.
\end{abstract}

Keywords: Work ethics, Motivation, Organizaion Climate and Performance.

\begin{abstract}
Abstrak
Tujuan penelitian adalah untuk mengetahui hasil analisis pengaruh etos kerja, motivasi, dan iklim organisasi terhadap kinerja Departemen Asset \& Office Management PT Semen Baturaja (Persero) Tbk, baik secara parsial maupun simultan. Penelitian ini merupakan penelitian kuantitatif, dengan metode eksplanasi, asosiatif, descriptive dan metode survey. Analisis data menggunakan analisis linear berganda dengan SPSS versi 25. Populasi dan sampel penelitian adalah seluruh personil Departemen Asset \& Office Management sebanyak 31 karyawan. Hasil uji-t secara parsial etos kerja, motivasi, dan iklim organisasi tidak berpengaruh terhadap kinerja, dengan hasil thitung etos kerja -0.053 < ttabel 2,04523, thitung motivasi $1<$ ttabel 2,04523, dan thitung iklim organisasi 1,839 dan < ttabel 2,04523. Hasil uji-F secara simultan etos kerja, motivasi dan iklim organisasi berpengaruh terhadap kinerja dengan hasil Fhitung 10,251 > Ftabel 2,93. Koefisien korelasi $(R)$ 0,730 menunjukan hubungan kuat positif dan koefisien determinasi (R2) 0,532 menunjukkan 53,2\% dari variabel kinerja Departemen Asset \& Office Management dapat dijelaskan variabel etos kerja, motivasi, dan iklim organisasi dan 46,8\% dipengaruhi oleh variabel lainnya. Sehingga dapat disimpulkan, jika etos kerja,
\end{abstract}




\section{8}

Irsan Yasdianto, Luis Marnisah, Fakhry Zamzam, Pengaruh Etos Kerja, Motivasi dan Iklim....

motivasi, dan iklim organisasi meningkat secara parsial, tidak akan meningkatkan kinerja Departemen Asset \& Office Management, tetapi jika ditingkatkan secara simultan maka kinerja Departemen Asset \& Office Management akan meningkat.

Kata Kunci: Etos Kerja, Motivasi, Iklim Organisasi, dan Kinerja.

\section{DASAR PEMIKIRAN}

Pengelolaan aset dan pelayanan umum seluruh site di PT Semen Baturaja (Persero) Tbk menjadi tanggung jawab Departemen Asset \& Office Management. Dengan tersebarnya personil di seluruh site dan perwakilan (Palembang, Baturaja, Panjang, Jakarta, Lubuk Linggau, Jambi) dan luasnya area yang merupakan tanggung jawab Departemen Asset \& Office Management maka pencapaian kinerja personil di Departemen Asset \& Office Management dipengaruhi oleh beberapa hal antara lain etos kerja, motivasi dan iklim organisasi.

Etos kerja merupakan salah satu faktor penentu dalam keberhasilan sumber daya manusia untuk mencapai tujuan dan sasaran perusahaan yang dipengaruhi oleh pertama perbedaan agama membuat cara berfikir, bersikap dan berperilaku seseorang menjadi berbeda sesuai dengan agama yang dianut. Kedua, perbedaan budaya juga dapat memengaruhi sikap mental, tekad, disiplin serta semangat bekerja karyawan. Ketiga, tinggi rendahnya etos kerja karyawan juga dapat terpengaruh dari ada atau tidaknya struktur politik yang mendorong karyawan untuk bekerja keras dan bisa menikmati hasil kerjanya dan keempat, kondisi lingkungan juga dapat memengaruhi kegiatan operasional organisasi.

Motivasi juga merupakan salah satu faktor yang menentukan pencapaian kinerja karyawan. Untuk berkoordinasi antar site mengenai pekerjaan, personil Departemen Asset \& Office Management telah melakukan komunikasi secara rutin dan kontinyu menggunakan fasilitas alat komunikasi seperti handphone, email maupun video conference, tetapi sering terjadi kendala teknologi sehingga koordinasi yang dilakukan belum maksimal. Dengan tersebarnya personil di Departemen Asset \& Office Management serta keterbatasan media komunikasi, dirasakan sulit untuk memberikan motivasi dari atasan terhadap bawahan sehingga komunikasi hanya terbatas pada koordinasi pekerjaan sehingga jika motivasi personil menurun akan menghambat tercapainya kinerja. 
Ekonomica Sharia: Jurnal Pemikiran dan Pengembangan Ekonomi Syariah Volume 6 Nomor 1 Edisi Agustus 2020 |99

Iklim organisasi juga merupakan salah satu faktor dalam pencapaian kinerja, iklim organisasi mempunyai peran yang sangat penting dalam meningkatkan kinerja karyawan. Iklim organisasi mengakibatkan munculnya pola lingkungan yang memunculkan motivasi serta fokus pada persepsi yang masuk akal dan berimbas pada pengaruh terhadap kinerja karyawan. Iklim organisasi yang kondusif dapat menciptakan suasana kerja yang nyaman, dengan suasana kerja yang nyaman, maka cenderung akan meningkatkan semangat karyawan sehingga kinerja akan tercapai.

Dengan keterbatasan jumlah karyawan untuk melaksanakan seluruh kegiatan di Departemen Asset \& Office Management maka seringkali terjadi rangkap pekerjaan yang mengakibatkan adanya kekeliruan akan peran, tugas, fungsi dan tanggung jawab karyawan. Selain hal tersebut, karyawan juga seringkali mendapatkan pekerjaan tambahan yang bersifat urgent dari top management yang terkadang tidak terencana sehingga menyebabkan pekerjaan rutin menjadi tertunda, hal ini dapat menyebabkan hasil kerja karyawan tidak tercapai.

\section{RUMUSAN MASALAH}

Dari hasil identifikasi masalah di atas, maka pencapaian kinerja Departemen Asset \& Office Management PT Semen Baturaja (Persero) Tbk akan dikaji melalui pengaruh dari variabel etos kerja, motivasi, dan iklim organisasi yang dirumuskan sebagai berikut; Bagaimanakah pengaruh etos kerja, motivasi, dan iklim organisasi secara parsial dan simultan terhadap kinerja Departemen Asset \& Office Management PT Semen Baturaja (Persero) Tbk?

\section{TUJUAN PENELITIAN}

1. Mengetahui hasil analisis pengaruh etos kerja, motivasi, dan iklim organisasi secara parsial terhadap kinerja Departemen Asset \& Office Management PT Semen Baturaja (Persero) Tbk

2. Mengetahui hasil analisis pengaruh etos kerja, motivasi, dan iklim organisasi secara simultan terhadap kinerja Departemen Asset \& Office Management PT Semen Baturaja (Persero) Tbk. 
100 Irsan Yasdianto, Luis Marnisah, Fakhry Zamzam, Pengaruh Etos Kerja, Motivasi dan Iklim....

\section{DESAIN PENELITIAN}

Penelitian ini merupakan penelitian kuantitatif yang menggunakan metode explanasi menjelaskan kedudukan variabel yang diteliti serta hubungan antara satu variabel dengan variabel lainnya. Untuk mengetahui hubungan antar dua variabel atau lebih digunakan metode penelitian asosiatif. Metode deskriptif digunakan untuk menggambarkan objek penelitian pada saat ini berdasarkan fakta di lapangan kemudian dianalisis dan diinterprestasikan. Untuk melakukan analisa data, penelitian ini menggunakan metode penelitian survey pada personil Departemen Asset \& Office Management di PT Semen Baturaja (Persero) Tbk (Siregar, 2015).

\section{POPULASI DAN SAMPEL}

Populasi dalam penelitian ini adalah seluruh karyawan yang berada di Departemen Asset \& Office Management PT Semen Baturaja (Persero) Tbk tahun 2019 yaitu sebanyak 31 orang karyawan. Menurut Arikunto dalam Raharjo (2013), jika populasi penelitian kurang dari 100 maka jumlah sampel yang diambil adalah keseluruhan populasi, namun jika populasi penelitian berjumlah lebih dari 100 maka sampel dapat diambil antara 10-15\% atau 20-25\% atau lebih. Jadi sampel penelitian ini adalah seluruh karyawan yang berada di Departemen Asset \& Office Management PT Semen Baturaja (Persero) Tbk yang berjumlah 31 orang

\section{TEKNIK PENGUMPULAN DATA}

Penelitian ini menggunakan metode kuesioner dan dokumentasi. Kuesioner adalah teknik pengumpulan data dengan membuat dan menyebarkan kuesioner (angket) yang berupa daftar pertanyaan atau pernyataan tertutup untuk memperoleh data primer secara langsung dari objek penelitian atau responden. Kuesioner digunakan untuk mendapatkan data mengenai etos kerja, motivasi, iklim organisasi, dan kinerja. Sedangkan dokumentasi adalah teknik pengumpulan data dengan mempelajari berbagai literature, jurnal dan penelitian sebelumnya, untuk memperoleh data-data sekunder. 
Ekonomica Sharia: Jurnal Pemikiran dan Pengembangan Ekonomi Syariah Volume 6 Nomor 1 Edisi Agustus 2020 | 101

\section{VARIABEL PENELITIAN}

\section{Variabel Etos Kerja}

Definisi konsepsual etos kerja pada penelitian ini adalah sikap atau kepribadian individu dalam menyelesaikan pekerjaannya dengan efisien dan efektif agar tercapai kinerja yang optimal.

Operasional variabel etos kerja pada penelitian ini mengadopsi pendapat dari Petty yang terdiri atas beberapa dimensi antara lain: a) dimensi keahlian interpersonal, b) dimensi inisiatif, dan c) dimensi dapat diandalkan. Adapun indikator dimensi keahlian interpersonal, yaitu terdiri dari: a) sikap, b) perilaku. Sedangkan indikator dimensi inisiatif, terdiri dari: a) efektif dan efisien, b) banyak ide. Dan indikator dimensi dapat diandalkan, terdiri dari: a) mengikuti petunjuk, b) jujur.

\section{Variabel Motivasi}

Definisi konsepsual motivasi pada penelitian ini adalah dorongan atau pemberian daya penggerak secara internal maupun eksternal yang dapat membangkitkan semangat diri sendiri maupun orang lain agar dapat mau bekerja efektif, bekerjasama dan terintegrasi dengan segala upaya untuk mencapai tujuan.

Operasional variabel motivasi pada penelitian ini mengadopsi teori motivasi kebutuhan McClelland yang terdiri atas beberapa dimensi, yaitu: a) dimensi kebutuhan untuk berafiliasi, b) dimensi kebutuhan untuk berprestasi, dan c) dimensi kebutuhan untuk berkuasa. Adapun indikator dimensi kebutuhan untuk berafiliasi terdiri dari: a) semangat untuk dapat bekerjasama, b) semangat akomodasi kepentingan lain. Indikator dimensi kebutuhan untuk berprestasi terdiri dari: a) upaya mencapai prestasi, b) semangat mendapatkan informasi terkini. Sedangkan indikator dimensi kebutuhan untuk berkuasa terdiri dari: a) berupaya menghormati pimpinan, b) berusaha menjaga wibawa.

\section{Variabel Iklim Organisasi}

Definisi konsepsual iklim organisasi pada penelitian ini adalah keadaan, kondisi dan karakteristik lingkungan tempat bekerja yang menjadi ciri khas sebuah organisasi yang terbentuk dari sikap, perilaku dan kepribadian seluruh anggota organisasi.

Operasional variabel iklim organisasi pada penelitian ini mengambil pendapat dari Wirawan yang terdiri atas dimensi: a) dimensi keadaan lingkungan fisik tempat kerja, b) 
102 | Irsan Yasdianto, Luis Marnisah, Fakhry Zamzam, Pengaruh Etos Kerja, Motivasi dan Iklim....

dimensi keadaan lingkungan sosial, c) dimensi pelaksanaan sistem manajemen. Adapun indikator dimensi keadaan lingkungan fisik tempat kerja, terdiri dari: a) tempat kerja, b) sarana dan prasarana. Indikator dimensi keadaan lingkungan sosial, terdiri dari: a) hubungan atasan dan bawahan, b) hubungan antar teman sekerja. Sedangkan indikator dimensi pelaksanaan sistem manajemen, terdiri dari: a) struktur organisasi, b) standar kerja.

\section{Variabel Kinerja}

Definisi konsepsual kinerja pada penelitian ini adalah suatu cerminan hasil yang dicapai oleh individu dari tindakan yang sesuai dengan tugas dan tanggung jawabnya dimana pelaksanaannya diawasi oleh orang-orang tertentu yaitu seorang atasan atau pimpinan dan dukungan dari organisasi.

Operasional variabel kinerja pada penelitian ini mengambil pendapat dari Mangkunegara yang terdiri atas beberapa dimensi antara lain: a) dimensi kualitas kerja, b) dimensi kuantitas kerja, c) dimensi keandalan, dan d) dimensi sikap. Indikator dimensi kualitas kerja, terdiri dari: a) penyelesaian rencana kerja, b) ketelitian dalam bekerja. Indikator dimensi kuantitas kerja, terdiri dari: a) sidak lapangan, b) tindaklanjut sidak lapangan. Indikator dimensi keandalan, terdiri dari: a) pendidikan, b) pengalaman. Indikator dimensi sikap, terdiri dari: a) loyal, b) kerja sama.

\section{RANCANGAN ANALISIS DATA}

Penelitian ini merupakan penelitian kuantitatif yang menggunakan kuesioner (angket) sebagai instrumen penelitian. Analisis kuantitatif merupakan analisis statistika yang dalam penelitian ini menggunakan analisis statistika deskriptif dan statistika impresial.

Analisis deskriptif adalah statistik yang digunakan untuk menganalisa data dengan cara mendeskripsikan atau menggambarkan data yang telah terkumpul sebagaimana adanya tanpa bermaksud membuat kesimpulan yang berlaku untuk umum atau generalisasi. Hasil analisis statistik deskriptif pada umumnya memuat informasi tentang jumlah sampel, nilai rata-rata, median, distribusi skewness, kurtosis, range, nilai maksimal, nilai minimal, nilai sum atau penjumlahan dan sebagainya yang didapat dari 
Ekonomica Sharia: Jurnal Pemikiran dan Pengembangan Ekonomi Syariah Volume 6 Nomor 1 Edisi Agustus $2020 \mid 103$

uji instrumen (uji validitas dan relibialitas) serta uji asumsi klasik (uji normalitas, uji linearitas, uji homogenitas, dan uji multikolinearitas) dengan menggunakan SPSS versi 25. (Sugiyono, 2004).

Statistik inferensial adalah jenis statistik yang berfokus pada pengolahan data sampel sehingga bisa diambil keputusan ataupun kesimpulan pada populasi. Analisis statistika inferensial ini dapat digunakan uji hipotesis maupun analisis regresi untuk mengambil kesimpulan dari penelitian ini. Uji hipotesis yang dilakukan adalah untuk melihat apakah ada pengaruh yang signifikan antara variabel independen dan variabel dependen baik secara parsial maupun simultan, sedangkan analisis regresi digunakan untuk melihat seberapa besar pengaruh variabel independen terhadap variabel dependen hubungan antara variabel independen dan variabel dependen. Dengan analisis regresi, kita bisa menyimpulkan variabel apa saja yang memiliki pengaruh secara signifikan pada sebuah penelitian (Yuvalianda, 2019).

\section{KERANGKA PEMIKIRAN TEORITIS}

Berangkat dari kerangka pemikiran teoritis, maka dapat digambarkan alur pikir penelitian sebagaimana tergambar dalam bagan alur pikir berikut:

Gambar 1

Bagan Alur Pikir

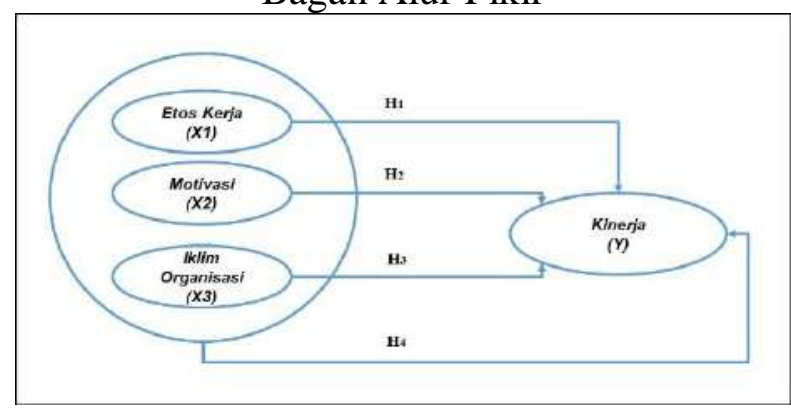

\section{HIPOTESIS PENELITIAN}

Dari kerangka pemikiran teoritis di atas, maka dalam penelitian ini mengajukan 4 (empat) hipotesis yang akan dicarikan jawabnya melalui penelitian adalah sebagai berikut:

$\mathrm{H}_{1}$ Diduga etos kerja berpengaruh terhadap kinerja Departemen Asset \& Office Management PT Semen Baturaja (Persero) Tbk. 
104 | Irsan Yasdianto, Luis Marnisah, Fakhry Zamzam, Pengaruh Etos Kerja, Motivasi dan Iklim....

$\mathrm{H}_{2}$ Diduga motivasi berpengaruh terhadap kinerja Departemen Asset \& Office Management PT Semen Baturaja (Persero) Tbk

$\mathrm{H}_{3}$ Diduga iklim organisasi berpengaruh terhadap kinerja Departemen Asset \& Office Management PT Semen Baturaja (Persero) Tbk

$\mathrm{H}_{4}$ Diduga etos kerja, motivasi, dan iklim organisasi secara simultan berpengaruh terhadap kinerja Departemen Asset \& Office Management PT Semen Baturaja (Persero) Tbk

\section{Hasil Uji t pada Hipotesis-1 $\left(\mathrm{H}_{1}\right)$}

Tabel 1

Pengaruh Etos Kerja Terhadap Kinerja

\begin{tabular}{|c|c|c|c|c|c|}
\hline \multicolumn{8}{|c|}{ Coefficients $^{\boldsymbol{a}}$} \\
\hline \multirow{3}{*}{ Model } & $\begin{array}{c}\text { Unstandardized } \\
\text { Coefficients }\end{array}$ & $\begin{array}{c}\text { Standardized } \\
\text { Coefficients }\end{array}$ & \multirow{2}{*}{$\mathrm{t}$} & \multirow{2}{*}{ Sig. } \\
\cline { 2 - 4 } & $\mathrm{B}$ & Std. Error & Beta & & \\
\hline Etos Kerja & $-0,017$ & 0,33 & $-0,013$ & $\mathbf{0 , 0 5 3}$ & $\mathbf{0 , 9 5 8}$ \\
\hline a. Dependent Variabel: Kinerja \\
\hline
\end{tabular}

Sumber : Output SPSS vr. 25

\section{Hasil Uji t Pada Hipotesis-2 $\left(\mathrm{H}_{2}\right)$}

Tabel 2

Pengaruh Motivasi Terhadap Kinerja

\begin{tabular}{|c|c|c|c|c|c|}
\hline \multicolumn{7}{|c|}{ Coefficients $^{\boldsymbol{a}}$} \\
\hline \multirow{3}{*}{ Model } & $\begin{array}{c}\text { Unstandardized } \\
\text { Coefficients }\end{array}$ & $\begin{array}{c}\text { Standardized } \\
\text { Coefficients }\end{array}$ & \multirow{2}{*}{$\mathrm{t}$} & \multirow{2}{*}{ Sig. } \\
\cline { 2 - 4 } & $\beta$ & Std. Error & Beta & & \\
\hline Motivasi & 0,365 & 0,365 & 0,274 & $\mathbf{1}$ & $\mathbf{2 6}$ \\
\hline a. Dependent Variabel: Kinerja
\end{tabular}

Sumber : Output SPSS vr. 25

\section{Hasil Uji t Pada Hipotesis-3 $\left(\mathbf{H}_{3}\right)$}

\section{Tabel 3}

Pengaruh Iklim Organisasi Terhadap Kinerja

\begin{tabular}{|c|c|c|c|c|c|}
\hline \multicolumn{7}{|c|}{ Coefficients $^{\boldsymbol{a}}$} \\
\hline \multirow{3}{*}{ Model } & \multicolumn{2}{|c|}{$\begin{array}{c}\text { Unstandardized } \\
\text { Coefficients }\end{array}$} & $\begin{array}{c}\text { Standardized } \\
\text { Coefficients }\end{array}$ & \multirow{2}{*}{$\mathrm{t}$} & \multirow{2}{*}{ Sig. } \\
\cline { 2 - 4 } & $\beta$ & Std. Error & Beta & & \\
\hline Iklim Organisasi & 98 & 0,325 & 0,494 & $\mathbf{1 , 8 3 9}$ & $\mathbf{0 , 0 7 7}$ \\
\hline
\end{tabular}

Sumber : Output SPSS vr. 25

\section{Hasil Uji F Pada Hipotesis-4 $\left(\mathrm{H}_{4}\right)$}

\begin{tabular}{|l} 
Tabel 3 \\
\begin{tabular}{|c|l|c|c|c|c|}
\hline \multicolumn{1}{|c|}{ ANOVA } \\
\hline Model & $\begin{array}{c}\text { Sum of } \\
\text { Squares }\end{array}$ & df & $\begin{array}{c}\text { Mean } \\
\text { Square }\end{array}$ & F & Sig. \\
\hline Regression & 584,026 & 3 & 194,675 & $\mathbf{1 0 , 2 5 1}$ & $\mathbf{. 0 0 0}^{\mathbf{b}}$ \\
\hline
\end{tabular} \\
a. Dependent Variabel: Kinerja \\
\hline
\end{tabular}

Sumber : Output SPSS vr. 25 
Ekonomica Sharia: Jurnal Pemikiran dan Pengembangan Ekonomi Syariah Volume 6 Nomor 1 Edisi Agustus $2020 \mid 105$

\section{ANALISIS DAN PEMBAHASAN}

\section{Pengaruh Etos Kerja Terhadap Kinerja Departemen Asset \& Office Management}

Hasil analisis uji-t variabel etos kerja mendapatkan nilai thitung sebesar -0.053 dimana nilai ini lebih kecil dari nilai $\mathrm{t}_{\text {tabel(}(0,05, n-2)} 2,04523$ dan nilai Sig. 0,958 > probabilitas 0,05 yang membuktikan bahwa secara parsial etos kerja tidak memiliki pengaruh terhadap kinerja Departemen Asset \& Office Management.

Hal ini mengkonfirmasi fakta di lapangan bahwa mayoritas karyawan memiliki tanggung jawab yang baik dalam menyelesaikan pekerjaanya tanpa pengawasan sesuai dengan arahan dari atasan sehingga terbangun hubungan yang positif antara atasan dan bawahan. Hubungan yang positif tidak hanya dibangun berdasarkan dengan selesainya pekerjaan saja tetapi juga dibangun oleh sikap ramah, saling menghargai, saling mendukung, saling memahami, saling menjaga komunikasi yang baik sehingga jika karyawan hanya fokus dalam menyelesaikan pekerjaannya saja tanpa memperhatikan hal lainnya maka kinerja karyawan tidak akan meningkat.

Karyawan di Departemen Asset \& Office Management juga telah diberikan kesempatan untuk menyampaikan ide-ide kreatif agar dapat meningkatkan kinerjanya dan tidak langsung merasa puas dengan kinerja yang biasa, walaupun belum semua ideide kreatif tersebut dapat direalisasikan. Beberapa karyawan juga belum memiliki keberanian dan percaya diri untuk mengemukakan ide-ide kreatifnya yang disebabkan oleh kurangnya pengetahuan, keahlian, dan pengalaman. Hal ini menyebabkan penyelesaian tindak lanjut hasil obervasi lapangan tertunda karena masih kurangnya inisiatif dan kreatifitas karyawan yang hanya menjalankan arahan atasan sehingga kinerja karyawan tidak akan meningkat.

Maka dapat disimpulkan bahwa etos kerja yang ada dalam diri karyawan Departemen Asset \& Office Management terbentuk dengan melibatkan banyak faktor antara lain pendidikan, motivasi dan iklim organisasi. Pendidikan dapat meningkatkan kualitas sumber daya manusia yang juga akan meningkatkan etos kerja, karyawan yang memiliki motivasi tinggi tentu akan memiliki etos kerja yang tinggi juga. Iklim organisasi yang mendukung akan memengaruhi karyawan dalam melakukan kegiatan untuk mengelola dan mengambil manfaat. Maka untuk meningkatkan kinerja 
106 | Irsan Yasdianto, Luis Marnisah, Fakhry Zamzam, Pengaruh Etos Kerja, Motivasi dan Iklim....

Departemen Asset \& Office Management peningkatan etos kerja harus diiringi dengan meningkatnya motivasi dan iklim organisasi.

\section{Pengaruh Motivasi Terhadap Kinerja Departemen Asset \& Office Management}

Hasil analisis uji-t secara parsial, diketahui bahwa motivasi tidak berpengaruh terhadap kinerja Departemen Asset \& Office Management dengan nilai Sig. 0,326> probabilitas 0,05 dan nilai $\mathrm{t}_{\text {hitung }} 1<\mathrm{t}_{\text {tabel }(0,05, \mathrm{n}-2)} 2,04523$. Hal ini mengkonfirmasi fakta di lapangan bahwa secara mayoritas karyawan di Departemen Asset \& Office Management setuju antar rekan kerja telah dibangun rasa saling menghormati yang merupakan salah satu faktor yang membentuk hubungan positif antar rekan kerja. Hubungan positif antar rekan kerja bukan saja dibentuk dengan adanya sikap saling menghormati, tetapi juga dalam bentuk memberikan dorongan kepada bawahan agar dapat berupaya untuk mencapai kinerja.

Karyawan di Departemen Asset \& Office Management juga telah diberikan kesempatan untuk mengembangkan kompetensi melalui pelatihan yang diselenggarakan secara internal maupun eksternal walaupun belum semua karyawan mendapatkan kesempatan yang sama untuk mengikuti pelatihan. Hal ini menyebabkan adanya perbedaan kompetensi yang dimiliki karyawan di Departemen Asset \& Office Management sehingga menyebabkan perbedaan pencapaian dalam menyelesaikan tindak lanjut observasi lapangan.

Maka dapat disimpulkan bahwa motivasi yang diberikan atasan pada bawahan atau sesama rekan kerja tidak dapat meningkatkan kinerja karyawan Departemen Asset \& Office Management, jika tidak diiringi oleh faktor motivasional yaitu faktor yang bersifat instrinsik atau hal yang mendorong karyawan untuk berprestasi dari dalam diri seseorang seperti etos kerja dan faktor hygiene yaitu faktor yang bersifat ekstrinstik atau hal yang mendorong karyawan untuk berprestasi dari luar diri seseorang seperti lingkungan kerja atau iklim organisasi. 
Ekonomica Sharia: Jurnal Pemikiran dan Pengembangan Ekonomi Syariah Volume 6 Nomor 1 Edisi Agustus $2020 \mid 107$

\section{Pengaruh Iklim Organisasi Terhadap Kinerja Departemen Asset \& Office Management}

Hasil analisis uji-t secara parsial, diketahui bahwa iklim organisasi tidak berpengaruh terhadap kinerja Departemen Asset \& Office Management dengan nilai Sig. $0,077>$ probabilitas 0,05 dan nilai $\mathrm{t}_{\text {hitung }} 1,839<\mathrm{t}_{\text {tabel }(0,05, \mathrm{n}-2)} 2,04523$. Hal ini mengkonfirmasi fakta di lapangan bahwa secara mayoritas karyawan di Departemen Asset \& Office Management setuju bahwa komunikasi yang dibangun antar sesama rekan kerja dapat membantu dalam menyelesaikan pekerjaan sehingga terbangun hubungan yang positif antar rekan kerja. Hubungan yang positif tidak hanya dapat dibangun dengan komunikasi saja, tetapi juga dengan menerapkan sikap saling menghormati, saling menghargai, bertanggung jawab dan saling memberikan dorongan semangat untuk mencapai penyelesaian kinerja. Adanya komunikasi yang baik menimbulkan rasa saling menolong yang kuat diantara karyawan Departemen Asset \& Office Management. Namun hal ini juga menyebabkan seringnya pekerjaan yang dilakukan karyawan tidak sesuai dengan tugas dan tanggung jawabnya sehingga pekerjaan utama menjadi seringkali terbengkalai atau tertunda karena mendahulukan pekerjaan tambahan sehingga kinerja tidak tercapai.

Karyawan di Departemen Asset \& Office Management juga telah mengetahui uraian tugas jabatan yang sesuai dengan struktur organisasi, tetapi belum semua karyawan di Departemen Asset \& Office Management memahami dengan detail peran, fungsi, tanggung jawab dan ruang lingkup jabatannya, sehingga untuk menindaklanjuti hasil observasi lapangan harus menunggu arahan dari atasan.

Maka dapat disimpulkan untuk meningkatkan kinerja karyawan Departemen Asset \& Office Management tidak hanya diperlukan peningkatan pemahaman karyawan mengenai peran, fungsi, tanggung jawab dan ruang lingkup pekerjaan sesuai jabatan, tetapi perlu ditingkatkan pula sikap, perilaku, tanggung jawab di dalam diri individu serta memberikan dorongan semangat dari atasan ke bawahan atau rekan kerja. 
108 Irsan Yasdianto, Luis Marnisah, Fakhry Zamzam, Pengaruh Etos Kerja, Motivasi dan Iklim....

\section{Pengaruh Etos Kerja, Motivasi, Dan Iklim Organisasi Secara Simultan Terhadap Kinerja Departemen Asset \& Office Management}

Hasil analisis uji-F variabel yaitu etos kerja, motivasi, dan iklim organisasi secara simultan mendapatkan nilai $F_{\text {hitung }}$ sebesar 10,251 dimana nilai tersebut lebih besar dari

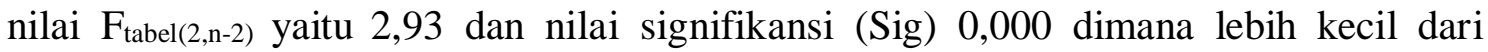
probabilitas 0,05 . Hasil analisis tersebut membuktikan bahwa secara simultan etos kerja, motivasi, dan iklim organisasi berpengaruh positif dan signifikan terhadap kinerja Departemen Asset \& Office Management serta berhasil mengkonfirmasi antara teori dengan data empiris di lapangan.

Meningkatnya kinerja dipengaruhi oleh faktor internal dan faktor eksternal. Faktor internal adalah faktor yang datang dari dalam diri individu seperti etos kerja dan motivasi, sedangkan faktor eksternal adalah faktor yang datang dari luar diri individu seperti iklim organisasi. Untuk meningkatkan kinerja Departemen Asset \& Office Management maka harus ditingkatkan pula secara simultan etos kerja, motivasi dan iklim organisasi. Artinya untuk membangun hubungan yang positif antar rekan kerja maka harus ditingkatkan secara bersama-sama antara sikap bertanggung jawab karyawan dalam bekerja walaupun tanpa pengawasan, membangun sikap saling menghormati dan membangun komunikasi yang baik antar rekan kerja.

Agar karyawan Departemen Asset \& Office Management dapat menyelesaikan tindak lanjut observasi lapangan secara konsisten dan kontinyu, maka harus memberikan kesempatan yang sama untuk karyawan dalam mengembangkan kompetensi, keahlian dan keterampilan sehingga timbul keberanian dan percaya diri untuk memberikan ide-ide kreatif serta meningkatkan pemahaman karyawan akan peran, fungsi, tanggung jawab dan ruang lingkup pekerjaan sesuai dengan uraian tugas jabatan.

Tabel 4

Besaran Pengaruh Etos Kerja, Motivasi, Dan Iklim Organisasi Secara Simultan Terhadap Kinerja Departemen Asset \& Office Management

\begin{tabular}{|c|c|c|c|}
\hline \multicolumn{4}{|c|}{ Model Summary } \\
\hline $\mathrm{R}$ & $\mathrm{R}$ Square & Adjusted $R$ Square & Std. Error of the Estimate \\
\hline $\mathbf{0 , 7 3 0}$ & $\mathbf{0 , 5 3 2}$ & 0,481 & 4,35783 \\
\hline \multicolumn{2}{|c|}{ aredictors: (Constant), $\mathrm{X}_{2}, \mathrm{X}_{1}$} & \\
\hline
\end{tabular}

Sumber: Output SPSS vr. 25 
Ekonomica Sharia: Jurnal Pemikiran dan Pengembangan Ekonomi Syariah Volume 6 Nomor 1 Edisi Agustus $2020 \mid 109$

Koefisien korelasi (R) antara etos kerja, motivasi, dan iklim organisasi secara simultan terhadap kinerja Departemen Asset \& Office Management diperoleh nilai sebesar $\mathrm{r}=0,730$. Nilai ini menunjukkan hubungan kuat positif antara etos kerja, motivasi, dan iklim organisasi terhadap kinerja Departemen Asset \& Office Management.

Kontribusi yang diberikan oleh variabel etos kerja, motivasi dan iklim organisasi secara simultan terhadap variabel kinerja Departemen Asset \& Office Management atau Koefisien Determinasi $\left(\mathrm{R}^{2}\right)=0,532$. Hal ini menunjukkan bahwa sebesar 53,2\% dari variabel kinerja Departemen Asset \& Office Management dapat dijelaskan oleh variabel etos kerja, motivasi, dan iklim organisasi, sedangkan sisanya yaitu sebesar $46,8 \%$ diterangkan oleh variabel lain yang tidak diteliti dalam penelitian ini.

Untuk meningkatkan kinerja, Departemen Asset \& Office Management dapat memberikan lebih banyak kesempatan kepada karyawan untuk menyampaikan ide-ide kreatif, memberikan kesempatan untuk mengembangkan kompetensi karyawan secara merata melalui pelatihan-pelatihan baik inhouse training maupun public training, dan dapat lebih memahami peran, tugas dan tanggung jawab personil, agar sesuai antara pekerjaan dan role profile jabatan sehingga pekerjaan dapat diselesaikan dengan efektif dan efisien dengan tidak mengenyampingkan rasa saling menghargai dan saling menghormati.

\section{SIMPULAN}

Berdasarkan hasil penelitian dan analisis data sebelumnya, maka diperoleh kesimpulan sebagai berikut:

1. Etos kerja secara parsial tidak berpengaruh positif dan signifikan terhadap kinerja Departemen Asset \& Office Management PT Semen Baturaja (Persero) Tbk, ini artinya walaupun karyawan telah memiliki kesadaran untuk bekerja dengan baik tanpa diawasi, namun jika tidak diiringi dengan sikap saling menghormati dan komunikasi yang baik maka tidak akan terbangun hubungan positif antar sesama rekan kerja yang menyebabkan kinerja Departemen Asset \& Office Management tidak meningkat. 
110 | Irsan Yasdianto, Luis Marnisah, Fakhry Zamzam, Pengaruh Etos Kerja, Motivasi dan Iklim....

2. Motivasi secara parsial tidak berpengaruh positif dan signifikan terhadap kinerja Departemen Asset \& Office Management PT Semen Baturaja (Persero) Tbk, ini artinya walaupun karyawan telah saling menghormati antar sesama rekan kerja, namun jika tidak diiringi dengan komunikasi yang baik dan tidak ada kesadaran karyawan untuk bekerja dengan baik tanpa diawasi maka tidak akan terbangun hubungan positif antar sesama rekan kerja yang menyebabkan kinerja Departemen Asset \& Office Management tidak meningkat.

3. Iklim organisasi secara parsial tidak berpengaruh positif dan signifikan terhadap kinerja Departemen Asset \& Office Management PT Semen Baturaja (Persero) Tbk, ini artinya walaupun komunikasi antar rekan kerja telah terjalin dengan baik dan dapat membantu menyelesaikan pekerjaan, namun jika tidak diiringi dengan sikap saling menghormati dan tidak ada kesadaran karyawan untuk bekerja dengan baik tanpa diawasi, maka tidak akan terbangun hubungan positif antar sesama rekan kerja yang menyebabkan kinerja Departemen Asset \& Office Management tidak meningkat.

4. Etos kerja, motivasi, dan iklim organisasi secara simultan berpengaruh positif dan signifikan terhadap kinerja Departemen Asset \& Office Management PT Semen Baturaja (Persero) Tbk, ini artinya jika telah diterapkan secara bersama-sama kesadaran karyawan untuk bekerja dengan baik walau tanpa pengawasan, sikap saling menghormati, serta telah terbentuk komunikasi dengan baik antar rekan kerja, maka akan terbentuk hubungan yang positif antar sesama rekan kerja, dan hal ini dapat meningkatkan kinerja Departemen Asset \& Office Management.

5. Kinerja Departemen Asset \& Office Management PT Semen Baturaja (Persero) Tbk dipengaruhi oleh variabel iklim organisasi yaitu sebesar 59,8\%, kemudian variabel motivasi sebesar 36,5\% dan yang terkecil adalah variabel etos kerja sebesar $-1,7 \%$.

\section{IMPLIKASI MANAJERIAL}

Strategi yang dapat dilakukan dalam rangka meningkatkan kinerja Departemen Asset \& Office Management PT Semen Baturaja (Persero) Tbk adalah: 
Ekonomica Sharia: Jurnal Pemikiran dan Pengembangan Ekonomi Syariah Volume 6 Nomor 1 Edisi Agustus $2020 \mid 111$

1. Memberikan kesempatan yang lebih banyak kepada karyawan untuk menyampaikan ide-ide kreatifnya.

2. Mengembangkan kompetensi karyawan secara rutin melalui pelatihan-pelatihan,

3. Melakukan penyesuaian antara pekerjaan yang dilakukan dengan role profile sehingga karyawan paham akan peran, tugas dan tanggung jawabnya.

\section{SARAN}

1. Departemen Asset \& Office Management dapat lebih memberikan kesempatan kepada karyawan untuk menyampaikan pendapat dan ide-ide kreatif.

2. Departemen Asset \& Office Management dapat lebih memberikan kesempatan yang sama kepada karyawan untuk meningkatkan kompetensi melalui pelatihanpelatihan baik inhouse training maupun public training dan juga sharing knowledge.

3. Agar karyawan dapat lebih memahami dan menjalankan pekerjaan sesuai dengan role profile.

4. Guna pengembangan ilmu manajemen, khususnya manajemen sumber daya manusia agar dapat dilakukan penelitian lanjutan dengan menambahkan variabel lain yang dapat meningkatkan kinerja Departemen Asset \& Office Management seperti variabel konflik, komitmen, kompensasi maupun reward. 


\section{DAFTAR PUSTAKA}

Agusta, L., \& Sutanto, E. M. (2013). Pengaruh Pelatihan Dan Motivasi Kerja Terhadap Kinerja Karyawan CV Haragon Surabaya. Agora, 1(3), 1399-1408.

Aqsariyanti, L., Sjahruddin, H., \& Razak, N. (2019). Pengaruh Etos Kerja dan IklimOrganisasi Terhadap Kinerja Karyawan. Jurnal Organisasi Dan Manajemen, l(1).

Aryadillah. (2018). Pengaruh Iklim Organisasi dan Motivasi Kerja Karyawan terhadap Kinerja Karyawan pada PT Midi Utama Indonesia Tbk. Cakrawala, 18(2), 157170.

Asi, S. P. (2013). Pengaruh Iklim Organisasi Dan Burnout Terhadap Kinerja Perawat RSUD dr. Doris Sylvanus Palangka Raya. Jurnal Aplikasi Manajemen, 11(3), 515523.

Bawelle, M., \& Sepang, J. (2016). Pengaruh Etos Kerja, Gairah Kerja Dan Disiplin Kerja Terhadap Kinerja Karyawan Pt. Bri Cabang Tahuna. Jurnal Emba, 4(5), 353-361.

Danila, \& Kore, J. R. R. (2019). Pengaruh Kompetensi Dan Motivasi Terhadap Kinerja Pegawai Di Dinas Pekerjaan Umum Bina Marga Provinsi Sumatera Selatan. Jurnal Ecoment Global, 4(2).

Darman. (2016). Teori-Teori Manajemen Dan Organisasi, Pengertian Kinerja. http://theorymanajemendanorganisasi.blogspot.com/2016/01/kinerja-pegawai.html

Divisi Human Resource. (2019a). Data Karyawan SMBR 2019.

Divisi Human Resource. (2019b). Pencapaian Kinerja Departemen Asset \& Office Management Tahun 2019.

Divisi Human Resource. (2019c). Role Profile Vice President Corporate Services Management.pdf.

Divisi Human Resource. (2020). Struktur Organisasi Divisi Corporate Services Management 2020.pdf.

Fikroturrofiah. (2014). Hipotesis Penelitian. Eurika Pendidikan. https://www.eurekapendidikan.com/2014/12/hipotesis-penelitian.html

Firdaus, \& Zamzam, F. (2018). Aplikasi Metodologi Penelitian (1st ed.). Deepublish Publisher.

GuruPendidikan. (2019). 18 Pengertian Hipotesis Menurut Para Ahli Terlengkap. https://seputarilmu.com/2019/11/hipotesis-menurut-para-ahli.html

Hadiansyah, A., \& Yanwar, R. P. (2015). Pengaruh Etos Kerja Terhadap Kinerja Karyawan PT. AE. Jurnal Al-Azhar Indonesia Seri Humaniora, 3(2), 150-158.

Herujito, Y. M. (2001). Dasar-Dasar Manajemen. Grasindo Gramedia widiasarana 
Indonesia.

Jagad.id. (2019). Pengertian Motivasi Menurut Para Ahli Dan Secara Umum. https://jagad.id/pengertian-motivasi-menurut-para-ahli-dan-secara-umum/

KajianPustaka. (2018). Pengertian, Dimensi, Faktor dan Pengukuran Iklim Organisasi. https://www.kajianpustaka.com/2018/01/pengertian-dimensi-faktor-danpengukuran-iklim-organisasi.html

Karauwan, R., Lengkong, V. P., \& Mintardjo, C. (2015). Pengaruh Etos Kerja, Budaya Organisasi, Dan Beban Kerja Terhadap Kinerja Pegawai Di Dinas Pekerjaan Umum Minahasa Selatan. Jurnal Emba, 3(3), 1196-1207.

Kesuma, B., \& Syamsuddin, H. (2019). Pengaruh Gaya Kepemimpinan Demokratis Dan Motivasi Terhadap Kinerja Karyawan PT. Panin Bank Cabang Atmo Palembang. Jurnal Ecoment Global, 4(2), 103-117.

Kustrianingsih, M. R., Minarsih, M. M., \& Hasiolan, L. B. (2016). Pengaruh Motivasi Kerja, Kepemimpinan Dan Iklim Organisasi Terhadap Kinerja Karyawan Pada Dinas Kebudayaan dan Pariwisata Kota Semarang. Journal of Management, 02(02), 1-13.

Permatasari, J. A., Musadieq, M. Al, \& Mayowan, Y. (2015). Pengaruh Disiplin Kerja Dan Motivasi Kerja Terhadap Prestasi Kerja Karyawan (Studi Pada PT BPR Gunung Ringgit Malang). Jurnal Administrasi Bisnis (JAB), 25(1), 86139.

Priansa, D. J., \& Garnida, A. (2015). Pengaruh Kepemimpinan Visioner Dan Etos Kerja Terhadap Kinerja Pegawai Bank Syariah Mandiri. Jurnal Ecodemica, III(1), 342347.

Putro, D. Y., Rahayu, S. R., \& Hendro, O. (2019). Pengaruh Kultur Organisasi, Motivasi Kerja, Dan Kompetensi Terhadap Kinerja Anggota Kepolisian Pada Polda Sumatera Selatan. Jurnal Ecoment Global, 4(1).

Radianto, A., \& Sunuharyo, B. S. (2017). Pengaruh Iklim Organisasi Dan Budaya Organisasi Terhadap Kinerja Karyawan (Studi Pada Karyawan PT. PG Krebet Baru Malang). Jurnal Administrasi Bisnis (JAB), 53(1), 14-20.

Raharjo, S. (2013). Teori Sampel dan Sampling Penelitian. Konsistensi. https://www.konsistensi.com/2013/04/teori-sampel-dan-sampling-penelitian.html

Raharjo, S. (2014a). Cara Melakukan Analisis Regresi Multiples (Berganda) dengan SPSS.https://www.spssindonesia.com/2014/02/analisis-regresi-multipes-denganspss.html

Raharjo, S. (2014b). Cara Melakukan Uji Homogenitas dengan SPSS beserta Contoh Lengkap. Spss Indonesia. https://www.spssindonesia.com/2014/02/ujihomogenitas-dengan-spss.html

Raharjo, S. (2014c). Cara Melakukan Uji Linearitas dengan Program SPSS. https://www.spssindonesia.com/2014/02/uji-linearitas-dengan-program-spss.html 
Raharjo, S. (2014d). Cara Melakukan Uji Normalitas Kolmogorov-Smirnov dengan SPSS.https://www.spssindonesia.com/2014/01/uji-normalitas-kolmogorovsmirnov-spss.html

Raharjo, S. (2014e). Cara Melakukan Uji Reliabilitas Alpha Cronbach's dengan SPSS.https://www.spssindonesia.com/2014/01/uji-reliabilitas-alpha-spss.html

Raharjo, S. (2014f). Cara Melakukan Uji Statistik Deskriptif dengan Software SPSS.https://www.spssindonesia.com/2014/01/uji-statistik-deskriptif-spss.html

Raharjo, S. (2014g). Cara melakukan Uji Validitas Product Moment dengan SPSS. https://www.spssindonesia.com/2014/01/uji-validitas-product-momen-spss.html

Raharjo, S. (2014h). Uji Multikolinearitas dengan Melihat Nilai Tolerance dan VIF SPSS.https://www.spssindonesia.com/2014/02/uji-multikolonieritas-denganmelihat.html Popular

Raharjo, S. (2015). Cara Uji Independent Sample T-Test dan Interpretasi dengan SPSS.https://www.spssindonesia.com/2015/05/cara-uji-independent-sample-t-testdan.html

Raharjo, S. (2016). Cara Melakukan Uji F Simultan dalam Analisis Regresi Linear Berganda.https://www.spssindonesia.com/2016/08/cara-melakukan-uji-f-simultandalam.html

Raharjo, S. (2020). Cara Membuat Tabel Distribusi Frekuensi dan Statistik Deskriptif dengan SPSS. Spss Indonesia. https://www.spssindonesia.com/2015/01/caramembuat-tabel-distribusi-frekuensi.html

Rinaldi, U. (2016). Dampak Disiplin, Etos Kerja Dan Iklim Organisasi Terhadap Kinerja (Studi Kasus Pada Pt Sentosa Pontianak). Jurnal Eksos, XI(1), 45-54.

Riyadi, S. (2011). Pengaruh Kompensasi Finansial, Gaya Kepemimpinan, Dan Motivasi Kerja Terhadap Kinerja Karyawan Pada Perusahaan Manufaktur Di Jawa Timur. Jurnal Manajemen Dan Kewirausahaan, 13(1). https://doi.org/10.9744/jmk.13.1.40-45

Seputarpengetahuan. (2017). 25 Pengertian Manajemen Sumber Daya Manusia Menurut Para Ahli. https://www.seputarpengetahuan.co.id/2017/07/25-pengertianmanajemen-sumber-daya-manusia-menurut-para-ahli.html\#: :text=Pengertian manajemen sumber daya manusia menurut Mangkunegara adalah suatu perencanaan, dalam rangka mencapai tujuan organisasi.

Setiawan, A. (2013). Pengaruh Disiplin Kerja Dan Motivasi Terhadap Kinerja Karyawan Pada Rumah Sakit Umum Daerah Kanjuruhan Malang. Jurnal Ilmu Manajemen (JIM), 1(4).

Setiawan, K. C. (2015). Pengaruh Iklim Organisasi Terhadap Kinerja Karyawan Level Pelaksana Di Divisi Operasi Pt. Pusri Palembang. Jurnal Psikologi Islami, 1(1), 23-32.

Siregar, S. (2015). Statistik Parametrik Untuk Penelitian Kuantitatif (F. Hutari (ed.); 3rd ed.). Bumi Aksara. 
StatistikCeria.

(2012).

Teori

Analisis

Deskriptif.

https://statistikceria.blogspot.com/2012/01/teori-analisis-deskriptif.html

Sumajouw, D. V., Adolfina, \& Uhing, Y. (2018). Pengaruh Iklim Organisasi, Etos Kerja Dan Pelatihan Terhadap Produktivitas Kerja Karyawan Pada PT. PLN (Persero) Rayon Manado Selatan. Jurnal Emba, 6(4), 3448-3457.

SumberPengertian.id.

(2019).

Pengertian

Etos

Kerja.https://www.sumberpengertian.id/pengertian-etos-kerja

Timbuleng, S., \& Sumarauw, J. S. (2015). Etos Kerja, Disiplin Kerja, Dan Komitmen Organisasi Pengaruhnya Terhadap Kinerja Karyawan Pada PT Hasjrat Abadi Cabang Manado. Jurnal Emba, 3(2), 1051-1060.

Yuvalianda. (2019). Memahami Statistik Inferensial Dan Perbedaannya Dengan Statistik Deskriptif. https://yuvalianda.com/statistik-inferensial/

Zamzam, F., \& Aravik, H. (2016). Manajemen SDM Berbasis Syariah, Bogor: CV. RWTC Success.

Zamzam, F. (2016). Teknik Dasar Menulis Proposal Tesis (A. Moeins (ed.)). NoerFikri.

Zamzam, F. (2017). Manajemen Iklim Organisasi (A. N. Moein (ed.); 1st ed.). CV. RWTC Success. 
116 | Irsan Yasdianto, Luis Marnisah, Fakhry Zamzam, Pengaruh Etos Kerja, Motivasi dan Iklim.... 